\title{
O ENSINO/APRENDIZAGEM DA LÍNGUA FRANCESA COMO FATOR DE INSERÇÃO CULTURAL PARA NÃO NATIVOS
}

\author{
Christianne Benatti Rochebois ${ }^{1}$
}

\begin{abstract}
Resumo: Nas últimas décadas, a França recebeu milhares de pedidos de asilo por ano, principalmente de estrangeiros do Leste europeu e da antiga União Soviética. A imigração neste caso é o resultado final de uma série de circunstâncias sócio-históricas, como única alternativa diante de uma situação de vida dolorosa. Uma vez no novo país, o "demandeur d'asile" - utilizaremos o termo francês referente a "pedinte de asilo" em português por considerarmos mais adequado - , entra num processo de recriação da identidade linguística e cultural. Este trabalho apresenta três estudos de caso de nacionalidades diversas (tchechena, iraniana e armeniana), em que uma professora de FLE (francês língua estrangeira), brasileira, se depara com a situação de reconstrução de significações e de elaboração de novas interpretações que dessem conta das "vidas de origem" e das vidas em transformação na nova sociedade.
\end{abstract}

Palavras-chave: Imigração. Ensino. Inserção

\begin{abstract}
In the last decades, France has received millions of political asylum requests every year, mainly by foreigners from Eastern Europe and the former Soviet Union. Immigration in this case is the final result of a series of socio-historical circumstances, as a sole alternative to their painful life situation. Once in the new country, he/she enters a process of conquering anew his/her cultural and linguistic identity. This paper aims at presenting three case studies of various nationalities (Chechen, Iranian,

and Armenian), whereby a Brazilian French as a Foreign Language teacher faces the challenge of reconstructing significations and elaborating new interpretations that could account for these foreigners' lives of origin and their lives in transformation in the new society.
\end{abstract}

Keywords: Immigration. Teaching. Insertion

\section{Introdução}

A integração das populações imigradas na sociedade francesa é um processo lento e complexo; que se inicia com a entrada no território, mas onde termina? Acreditar que é com a aquisição da

\footnotetext{
${ }^{1}$ Professora de língua francesa do Departamento de Letras e Artes da Universidade Federal de Viçosa. Contato: chrisrochebois@ hotmail.fr.
} 
nacionalidade, seria desconhecer a realidade das trajetórias individuais e a interação com a nova sociedade. Primeiramente, o fato migratório é antigo na França, e os fluxos de migração variaram muito no último século. Sua origem e motivação se diversificaram extremamente, abrangendo desde as necessidades de mão de obra do século XIX até os movimentos, no espaço europeu de hoje, de populações provenientes majoritariamente de outros continentes e do que se chama de Europa do Leste. Além disso, a integração dessas pessoas recobre domínios muito variados, do social ao econômico, passando pelo cultural e pelo educativo.

O "velho continente" é atualmente a primeira região de imigração no mundo. Até os anos 80, era a América do Norte que recebia o maior número de imigrantes, mas hoje é a União Europeia que acolhe mais pessoas. Desde 1992, em média, 1,2 milhões de migrantes se instalam a cada ano na Europa ocidental, em comparação aos 800000 nos EUA e no Canadá.

Os movimentos migratórios mundiais, no fim do século XX, são alimentados por tensões e problemas estruturais nascidos há longo tempo, reforçados pelo desaparecimento da "cortina de ferro". No sudeste da Europa, o desabamento de antigas estruturas, após 19901991, provocou uma avalanche de refugiados. Os dois principais países de origem foram a Iugoslávia e a Albânia. A república federal e multiétnica da Iugoslávia se desmembrou durante uma longa crise econômica e política provocada pelos interesses irreconciliáveis dos diferentes Estados da Federação e das disputas nacionalistas. A guerra na ex-Iugoslávia transformou milhões de pessoas em apátridas. Centenas de milhares delas se refugiaram em outros estados europeus, onde lhes foi acordada uma proteção humanitária provisória em virtude das cláusulas da Convenção de Genebra sobre os refugiados. Uma série de guerras - na Eslovênia em junho-julho 1991, na Croácia de junho de 1991 a janeiro de 1992, na Bósnia-Herzegovina de abril de 1992 a novembro de 1995 — trouxe de volta atrocidades cometidas contra a população civil que os países do mundo ocidental não acreditavam mais possíveis desde a Segunda Guerra Mundial. Discursos sobre "purificações étnicas", que se pensava estarem calados há muito tempo, renasceram numa realidade dura e devastadora. Os estragos mais sérios, as consequências materiais, físicas 
e psíquicas mais graves para a população civil foram os da guerra da Bósnia-Herzegovina. Após o fim da guerra, em 1996, as purificações étnicas recomeçaram nos territórios. As minorias foram privadas dos seus meios de subsistência, foram expulsas de suas habitações, violadas, humilhadas, roubadas e dizimadas.

A diversidade das pessoas de origem estrangeira que vive na França hoje em dia corresponde a uma diversidade de percursos, de projetos e de línguas. Entre as diversas vias de obtenção da nacionalidade francesa, vamos observar de perto o caminho percorrido pelos "demandeurs d'asile". São pessoas que têm, desde a sua chegada no país, duas motivações fortes e ao mesmo tempo opostas: a primeira, representada por problemas políticos (torturas, prisões, assassinatos, histórias de vida e de morte) ou econômicos graves; a segunda, alimentada pelo sonho de habitar e de fazer parte da vida do "paraíso", do país dos Direitos do Homem.

$\mathrm{Na}$ França, os "demandeurs d'asile" políticos, se aceitos, obtêm um documento de refugiado e um documento de residente, válidos por dez anos e renováveis. Para isto, eles devem, num primeiro momento, solicitar o status de "demandeur d'asile". No começo dos anos 90, para fechar suas fronteiras após um pico de pedidos, a França reduziu as vantagens acordadas aos "demandeurs d'asile". Desde 1991, a autorização de trabalhar lhes foi suprimida. Em 1992, foram criadas nos aeroportos, zonas de espera, pelas quais passam os estrangeiros que chegam com a intenção de demandar o asilo político. Uma seleção é feita para descartar aqueles cuja demanda de asilo é "infundada". A partir destas zonas, as autorizações de entrada no território são de aproximadamente $90 \%$. O candidato pode, então, apresentar um pedido à OFPRA (Ofício de Proteção dos Refugiados e Apátridas), sob a tutela do Ministério das Relações Exteriores. A França interpreta de maneira restrita a Convenção de Genebra. Os refugiados devem trazer as provas materiais das violências que sofreram, e somente as vítimas do Estado podem se beneficiar do status de refugiado político. O tempo médio do processo desde a primeira visita à prefeitura até a obtenção de uma primeira resposta da OFPRA é de quinze meses atualmente.

Na região de Franche-Comté, mais especificamente no Departamento

${ }^{1}$ Como já assinalado no resumo, vamos manter a expressão "demandeur d'asile" em francês. 
do Doubs, no fim de 1999, o número elevado dos pedidos de asilo² provocou uma forte mobilização da Direção Departamental dos Assuntos Sanitários e Sociais, a DDASS, e de instituições sociais para colocar em prática um dispositivo de recepção, de alojamento e de acompanhamento. O grande número de chegadas neste departamento é decorrente principalmente da sua posição geográfica, pois é uma região de convergência de fronteiras a que os migrantes têm acesso clandestinamente, através do pagamento de uma grossa soma de dinheiro a "passantes". Estes atravessam as fronteiras em caminhão, através de estradas clandestinas durante a noite, e abandonam os futuros "demandeurs d'asile" em ruas próximas da DDASS de alguma cidade. Até este momento, o país de chegada é totalmente desconhecido dos passageiros.

A DDASS acolhe os "demandeurs d'asile" recém-chegados, faz uma avaliação global de sua situação e os orienta para uma das estruturas com disponibilidade no departamento. Besançon, capital do Doubs, dispõe de oito organismos, com trezentas e oitenta e quatro vagas. Estes organismos são divididos em três formas de estrutura: os CADA (Centro de Recepção de "Demandeurs d'Asile"), o CAUDA (Centro de Recepção de Urgência de "Demandeurs d'Asile") e também vagas disponíveis em apartamentos ou hotéis, normalmente reunidas num mesmo prédio.

No quadro das missões do CAUDA, o centro é comprometido a assegurar ao recém-chegado a primeira recepção, o alojamento, a alimentação, a higiene, cuidados médicos e acompanhamento do processo de demanda de asilo. Sua equipe é composta por um diretor, um chefe de serviço, uma secretária, dois intérpretes (de línguas serbo-croata, albanesa e russa), uma professora de francês, quatro assistentes sociais, dois vigias e um técnico de manutenção.

Os "demandeurs d'asile" acolhidos pelo CAUDA recebem acompanhamento administrativo ligado à constituição do dossiê de demanda de asilo; acompanhamento social, no momento de saída do Centro, para os residentes que obtém o status de refugiado; acompanhamento total para tudo o que for preciso em relação à saúde

\footnotetext{
${ }^{2}$ Informações recolhidas através da documentação verificada no CAUDA - Centre D’Accueil D’Urgence de Demandeurs d'Asile de Besançon.
} 
(consultas, traduções, internações, tanto dos pais quanto das crianças); escolarização para todas as crianças menores de 16 anos; cursos de francês para os adolescentes acima de 16 anos e os adultos; saídas culturais e viagens de férias para as crianças; refeições coletivas; e uma soma mensal para gastos pessoais.

\section{O Objetivo "Inserção"}

De setembro de 2001 a janeiro de 2004, trabalhei como professora de FLE (Francês Língua Estrangeira) no CAUDA de Besançon. Comecei como voluntária com um grupo de dez pessoas para as quais dava aula duas vezes por semana (num total de três horas). Rapidamente, o grupo cresceu e tive que dividi-lo em dois. Como a formação em língua não era obrigatória, a assiduidade e a melhora da comunicação entre a administração e os alunos provocaram a criação de um cargo de professor no Centro. A partir daí, vários grupos de alunos de níveis diferentes foram constituídos. Por causa da frequente entrada e saída de residentes, os grupos se transformavam, havendo sempre diversidade de línguas, de percursos, de projetos. Constatamos que a organização da sociedade francesa é de tal forma funcional que a utilização da língua não é obrigatória na vida cotidiana, sobretudo para o "demandeur d'asile", que é alojado entre outros estrangeiros com quem ele pode se comunicar normalmente na sua língua de origem, não se esquecendo de que no Centro há um intérprete disponível para servir de intermediário entre o "demandeur d'asile" e a administração. Ele pode fazer compras, estar alojado, ter a alimentação assegurada e receber um pecúlio mensal. A aprendizagem da língua se torna realmente opcional.

Por outro lado, nós não queríamos nos contentar com o objetivo tradicional dos cursos de língua para migrantes, quer dizer, obter o acesso a uma competência de sobrevivência. É lógico, era preciso que os alunos fossem capazes de responder a necessidades imediatas, de "se virar" no dia a dia. Mas tratava-se também de superar o obstáculo que constitui a ausência de contatos com os nativos do novo país, de trabalhar a língua francesa como o meio de se recriar através de uma nova identidade cultural e linguística que fosse compatível com as vidas de origem e sua inserção na sociedade francesa. 


\section{A Evolução da formação linguística no CAUDA de Besançon}

Quando apresentei minha candidatura para ensinar o francês no CAUDA de Besançon, o fato de ser de origem brasileira surpreendeu o diretor. Ele deixou claro que poderíamos fazer uma experiência, mas que ele achava que seria muito difícil para mim e para os residentes também, visto a mistura de culturas tão distantes. No primeiro dia de aula, os alunos eram numerosos e curiosos — o diretor havia anunciado que a professora era brasileira. Tive que acrescentar à "classe zero" todo um vocabulário relativo ao futebol, à Amazônia e às praias do Rio de Janeiro. Tudo isso relaxou, fez rir e sonhar pessoas que saíam de conflitos catastróficos e mortíferos. Um mês após, o número de alunos tinha dobrado, e eles esperavam com impaciência os dois dias da semana em que tinham curso de francês. Aprender a língua francesa tinha se tornado um prazer, um verdadeiro momento de relaxamento e, além disso, começavam a compreender que tinham necessidade deste aprendizado para permanecer e viver no novo país. Para completar, ver uma brasileira se expressar e ensinar o francês, ou seja, alguém que vinha também de longe como eles, e de uma realidade tão diferente da realidade francesa, lhes permitia entender que para eles também era possível aprender e viver na França.

Para mim, era uma experiência extraordinária. Chegar à França e me encontrar quase imediatamente num Centro de recepção de "demandeurs d'asile". Primeiramente, não sabia que este tipo de instituição existia e não fazia nenhuma ideia de seu funcionamento. Estar diante de um grupo de pessoas que haviam vivido guerras que eu só conhecia através de jornais e da televisão era uma experiência nova para mim.

Após as primeiras aulas sem nenhum material didático, a preocupação em encontrar o que seria mais adaptado a esta situação de plurilinguismo tão delicada era cada dia mais angustiante. Consultei a direção do Centro, mas ela se contentou em explicitar o objetivo visado com a criação da formação FLE: uma independência mínima, certa autonomia para os residentes na vida diária, poder ir a consultas médicas, fazer compras, enfim, sair na cidade sem a presença do intérprete.

A partir disso, fiz uma pesquisa nas bibliotecas e livrarias, mas 
não encontrei material específico de aprendizagem da língua para este público particular. Fato que me surpreendeu, porque o ensino da língua a adultos imigrantes não era uma situação nova na França. Há alguns anos a França compreende sua diversidade de público adulto estrangeiro, em particular, adultos imigrantes econômicos e políticos que apresentam diferentes níveis de escolarização. $\mathrm{O}$ que mais me inquietava era a constatação de que se tratava de um ensino fortemente ligado ao social, dito de outra forma, a uma inserção social muito importante e mesmo vital para os alunos. Como não encontrei nenhuma metodologia apropriada, optei por trabalhar com o mesmo método que tinha empregado nos dois últimos anos no Brasil, o método "Panorama".

O livro I do método, além de apresentar gradualmente o vocabulário, a gramática e situações de comunicação, trabalha pequenos textos e filmes da vida cotidiana do mundo francófono, propondo uma grande variedade de temas que envolvem o aprendiz em debates e confrontações entre culturas.

Dois anos após o início da formação, apresentamos uma estrutura organizacional bem maior. O número de alunos era diverso, principalmente em função de fatores externos, como por exemplo, os encontros com o intérprete para tratamento do dossiê, com a saúde pública para controles médicos, com o Socorro Católico e, finalmente, a viagem a Paris para a audiência na OFPRA. Todo este conjunto de obrigações administrativas representava momentos difíceis para os "demandeurs d'asile".

Fugir do país de origem, abandonar a família, a profissão, a casa, a cultura e a língua. Ser obrigado a fazê-lo (na maioria dos casos) por uma questão de sobrevivência e, para isto, viver em condições perigosas, chegar a um novo país e se encontrar durante longos meses numa situação angustiante de espera, ser ou não ser aceito pelo novo país. Todas estas inquietudes do passado, acrescentadas às incertezas do futuro e aos desafios do momento presente, a aquisição de novos hábitos de vida, de comportamento e de fala. Bem rapidamente eles entendem que o mais importante para o processo de inserção na sociedade que os recebe é aprender a compreender e se fazer compreender pelos nativos. Os que chegam, neste primeiro momento, a ultrapassar a apreensão de se reconstituir como sujeito falante, batem timidamente na porta da sala de aula. 
Certamente, um pouco mais que em outras situações didáticas, o trabalho de construção desse processo de ensino/aprendizagem é baseado numa mistura de culturas. É uma conjugação de experiências, de línguas e de necessidades que determinam o caminho seguido por cada grupo. $\mathrm{O}$ método adotado era sempre o ponto de partida, mas as atividades eram bem diversificadas. Nesta situação plurilíngue, em que as pessoas estão expostas a mudanças constantes de estado de espírito, o professor deve ter uma grande leveza para sentir, acompanhar e apoiar os alunos. Mudar no último minuto o plano de aula se tornou um procedimento normal. Ou mesmo passar o tempo da aula discutindo novos problemas e também a melhor maneira de gerenciar os novos progressos.

O esquema de horários e a constituição dos grupos eram muito

flexíveis. Se o CAUDA passava por um período de chegada massiva de novos "demandeurs", toda a organização da formação linguística era mudada para se adaptar aos alunos. E se, ao contrário, se tratasse de um momento mais calmo, tentávamos fazer aulas particulares extras para aqueles que tinham mais dificuldade e também para os que avançavam a passos largos. A formação de francês acompanhava esta "recepção de urgência" sem esquecer, no entanto, que se tratava de um espaço social constituído e não devotado totalmente ao ensino da língua, mas a uma educação da linguagem.

\section{Ruptura, preservação, construção}

Se “a apropriação de uma língua estrangeira é um processo de aculturação" (VERONIQUE, 1994), nós podemos nos perguntar em que este processo é ligado à relação entre o aluno de língua estrangeira, sua língua e sua comunidade de origem de um lado, a língua e a comunidade de recepção por outro lado. O "demandeur d'asile" se vê situado entre dois lugares sociolinguísticos. O lugar de nativo de uma língua de origem, ontem e além, e o lugar de estrangeiro, locutor não-nativo, hoje na França.

A dualidade da posição do estrangeiro no espaço social lhe assinala um lugar ambíguo no jogo paradoxal entre distância e proximidade pois ele se distancia ou chega num grupo constituído. (SIMMEL, 1999) 
Quando os alunos tomaram a decisão de imigrar, eles o fizeram como indivíduos, mesmo que não soubessem claramente qual seria sua vida alhures. A imigração é o resultado final de uma série de circunstâncias socio-históricas, como a única alternativa face a uma situação de vida dolorosa, que não teria sido possível sem uma predisposição à mudança e à ruptura com o passado. A imigração se situa, portanto, numa situação de crise. Diante do choque de seu novo ambiente cultural, o imigrante se sente mais ou menos estimulado a modificar seus esquemas de interpretação e de comportamento. Uma vez no novo país, o "demandeur" se encontra numa situação fortemente diglóssica (na medida em que sua língua de origem não é considerada como língua de uso) e a recriação identitária, linguística e cultural provoca num primeiro momento:

- seja o recuo, a negação, sintoma da dificuldade face a sua marginalização momentânea;

- seja uma desalienação por uma reafirmação da identidade social do sujeito na sua língua;

- seja um esforço sofrido, alcançado no dia a dia através de um processo de recriação, de recuperação de uma identidade sociolinguística.

Nós tentamos captar estas múltiplas reações (que podem mesmo ser fases sucessivas na história de um mesmo indivíduo) através de enquetes com alguns alunos ${ }^{3}$. A escolha das pessoas não foi fácil. A ideia era escolher um certo número de "demandeurs" que pudessem expressar as diferentes perspectivas na situação de recepção de urgência. Não levamos em conta a idade, visto que se tratava sempre de adultos (exceto alguns raros casos de adolescentes), nem o nível socio-cultural. Os critérios adotados foram o desejo de inserção manifestado por um grande interesse pelo aprendizado da língua, a frequência constante nas aulas e a vontade de trocar "habitus comunicativos" entre as culturas envolvidas (a de origem, a de recepção e também as outras presentes no grupo respectivo). Quisemos também que eles pertencessem a nacionalidades diferentes, para ter uma representação de uma parte da área geográfica que chamamos de Europa do leste. 
Através destes critérios, o grupo escolhido se constituiu de cinco mulheres e um único homem. Neste estudo, nos ateremos a três alunos: uma iraniana, uma armeniana e um tchetcheno. Para situá-los, recolhemos alguns dados de suas biografias, estimando a importância do vivido que provocou o pedido de asilo. A entrevista ${ }^{3}$ foi feita durante os primeiros meses de estadia na França, enquanto os alunos ainda não tinham muito tempo de imersão na vida francesa. Tratava-se, verdadeiramente, para eles, do momento de inscrição social num novo contexto local.

Quando foi perguntado pela primeira vez a estas pessoas se elas aceitavam ou não ser entrevistadas, seus olhares foram de surpresa e temor, e tivemos que explicar que era uma pesquisa pessoal, de maneira nenhuma ligada a procedimentos administrativos. As entrevistas foram realizadas no local onde o aluno se sentia mais à vontade: algumas na sala de aula, uma no quarto do residente e outra em minha casa. Foi lhes dado também a escolha de estarem ou não acompanhados de um intérprete. Mesmo que todos os seis tivessem um nível linguístico suficiente para compreender e para se expressar em francês, duas pessoas preferiram, nesta situação, utilizar a língua de origem.

A entrevista foi semidirigida, com variações de graus de implicação da parte dos entrevistados. O desafio consistiu em ultrapassar os simples enunciados individuais para fazer emergir aspectos fundamentais que permitissem compreender o fenômeno do grupo, mas, em geral, eles se limitaram às suas próprias histórias de vida.

Vamos apresentar os dados dos alunos, as respostas que consideramos mais significativas e tentar tecer alguns comentários sobre nossos estudos de caso.

\section{Estudos de caso}

1) Nome: Karin

País de origem: Armênia

Idade: 32 anos

Profissão: Contadora

${ }^{3}$ As transcrições completas das entrevistas estão disponíveis com o autor. 
Nível de escolaridade: Diploma em Gerente comercial (dois anos de estudos numa escola de comércio)

Chegada à França: Dezembro de 2002

Percurso migratório: Karin terminou seus estudos em 1989. Trabalhou alguns anos como vendedora, e logo após o nascimento de seus filhos parou de trabalhar. Ela e seu marido são armenianos, mas moravam na Geórgia. Em setembro de 2002, seu marido viajou a trabalho e não voltou na data prevista. Ela foi à polícia para assinalar seu desaparecimento, mas achava que a polícia nada fez para encontrá-lo "porque somos armenianos e na Geórgia os armenianos são o alvo do nacionalismo"4. Após ter recebido uma ameaça de morte pelo telefone, ela partiu com suas crianças para a casa de amigos. Finalmente, no início de novembro, seu marido voltou, num estado físico deplorável e explicou-lhe que havia sido sequestrado, jogado num fosso, humilhado, violentado e torturado. Imediatamente, eles decidiram partir da Geórgia porque ficar seria muito perigoso. Alguns amigos os ajudaram com os passaportes, os vistos e as passagens de avião. No início de dezembro, chegaram a Paris. "Como nós ignorávamos aonde ir, tentamos interrogar alguns passantes, mas ninguém nos compreendia.

Passamos a noite perto da estação e na quinta-feira, 5 de dezembro, encontramos um rapaz que falava um pouco a língua russa. Esta pessoa nos explicou que seria melhor se partíssemos para Besançon. Ele nos acompanhou até a estação, nos ajudou a comprar as passagens de trem e nos aconselhou a ir à Prefeitura assim que chegássemos, de onde nós seríamos guiados."3

A entrevista com Karin aconteceu no dia 4 de abril de 2003, na sala de aula do CAUDA, e ela não quis a presença do intérprete.

\begin{abstract}
"Na minha casa... russo e georgiano. Sempre. Mas... nós olhamos muito a televisão francesa e com os vizinhos... francês."

"Não. Na Geórgia, na Armênia não tem francês. Nós falamos inglês porque... o trabalho do meu marido, é preciso falar inglês [ele era controlador de voo num aeroporto]."
\end{abstract}

\footnotetext{
${ }^{4}$ Extrato de seu dossiê escrito originalmente em língua russa, traduzido no Centro pelo intérprete para o francês, e no texto, traduzido para o português pela autora.
} 
"Sim mas... depois. Na minha família, George [seu marido] pensa muito nos problemas. É importante que uma pessoa aprenda bem o francês. Para falar na escola, no médico, estudar com as crianças, começar a existir de novo. Sou eu. George pensa em outras coisas."

"Eu faço tudo sozinha. Eu não preciso de intérprete, eu não quero que outra pessoa fale por mim, da minha vida. Eu faço tudo para meu marido e as crianças. Meus filhos também, eles já falam bem francês."

"O mais difícil é meu marido em casa. Necessidade de trabalhar. Ele não está bem. É difícil, muito tempo esperar a resposta. Para a cabeça não é bom."

"Eu estudo muito em casa. Na escola, mais. Aqui eu... coisas novas. Como falar, a gramática, como fazer... viver... compreender as pessoas francesas. Na rua não. Os franceses não gostam de falar com as pessoas que não são francesas."

"O francês é o nosso futuro, nova vida. Para ficar na França, trabalhar... Eu estudei inglês muitos anos na Geórgia e na Armênia. E hoje, para mim, o francês é o mais importante. Eu não quero voltar."

$\mathrm{Eu}$ poderia dizer que desde o início da formação do francês no CAUDA, Karin é a residente que levou mais a sério aprendizagem do francês. Imediatamente após sua chegada, ela veio me procurar para pedir aulas. Nos dias em que não podia vir por causa das crianças ou por formalidades administrativas, ela se justificava e pedia aulas de reposição. Sempre demonstrou um enorme interesse, era a aluna que conseguia estruturar seus pensamentos com mais lucidez. Séria e sempre concentrada, foi somente no terceiro mês que começou a relaxar e a se dirigir às outras pessoas do seu grupo. Seu marido a acompanhava sempre e, quando possível, seus filhos também. Mas era evidente que ela os obrigava a vir. Tudo o que era pedido em sala de aula a alguém de sua família passava antes por ela. A pergunta era feita, ela os olhava, e com paciência e firmeza, lhes explicava na língua russa e lhes dava elementos para a resposta. Mesmo nos momentos de leitura ou de apresentação de diálogos, ela os corrigia ou ditava a pronúncia correta em voz baixa. Tudo isso não os impediu de progredir também, mas, no que diz respeito a ela, seu avanço foi a passos de gigante em francês. $\mathrm{O}$ fato de falar inglês fluentemente ajudou-a em relação ao alfabeto e ao vocabulário. Culturalmente era muito aberta. 
Mulher, e possuidora de uma boa bagagem cultural, queria saber tudo sobre os hábitos de vida dos franceses, mas ao mesmo tempo, mantendo sempre uma atitude protetora de sua família. Quando lhe propus um período de aulas particulares para sua família, aceitou imediatamente, e sua atitude nessas aulas era mais tranquila. Frequentou a formação somente durante seis meses porque sua família foi transferida a um CADA na cidade de Montbéliard. Para ela, o aprendizado do francês constituiu o ponto central, o meio que encontrou neste primeiro momento de inserção para se fortificar e se proteger.

2) Nome: Pari

País de origem: Irã

Idade: 43 anos

Profissão: Secretária numa agência de publicidade

Nível de escolaridade: $2^{\circ}$ grau

Chegada à França: outubro de 2002

Percurso migratório: Casada e mãe de duas crianças, desde 1996 Pari começou a organizar manifestações feministas em Teerã. Por não suportar o uso obrigatório do véu na rua, algumas vezes ela saiu com a cabeça nua. Foi cuspida, agredida e insultada. Na saída de uma manifestação no fim de 2002, foi aprisionada e torturada durante dois dias. Sua condição de "laica" atraía ainda mais discriminação. Desde que soube a data fixada para o seu "julgamento", deixou o país com seus dois filhos. Chegando a Paris de avião, imediatamente pegou o trem para Besançon, onde tem uma irmã e dois sobrinhos, que ali moram há trinta anos.

A entrevista com Pari aconteceu em minha casa, a seu pedido, em 6 de maio de 2003. Estava acompanhada de sua irmã que fala fluentemente francês e que fez a tradução. Pari falou somente em língua persa.

"Eu falo sempre em persa, sempre. Com meus filhos, minha irmã e meus

amigos."

"Eu falo inglês, um pouco. Mas na minha casa, no Irã, há muitos paquistaneses e com eles falamos em inglês."

"Sim. Meu pai estudou francês no colégio e no segundo grau também, na sua época. Depois da Revolução, eles fecharam todas as escolas estrangeiras. Na época do meu pai o francês representava a grande cultura do mundo. $\mathrm{E}$ 
com ele, eu aprendi a respeitar esta cultura. É por isso que minha irmã veio estudar aqui."

"Não. Eu quero muito. Chegar da aula e rever tudo o que nós trabalhamos na escola, mas meus filhos não estão bem aqui, na França. Então, eu coloco meu caderno sobre a cama esperando ter tempo à noite, mas eles me cansam tanto que eu acabo dormindo. Eles fazem terapia, depois tudo vai ficar melhor."

"Sempre com minha irmã. Não há intérprete da nossa língua persa aqui em

Besançon."

"A angústia dos meus filhos. E eu acredito que a culpa seja minha. Eu tinha medo de tudo no Irã e terminei por transmitir esse medo para eles. Hoje a gente não consegue sair disso. Não ainda."

"O mais difícil? Escrever. Não é o meu alfabeto. Mas eu já o conhecia por causa do inglês."

"Não. Enquanto eu ainda não sei falar a língua francesa, não me interessa saber como eles vivem aqui na França. Depois, sim. Vou poder contar minha vida, minha experiência, me localizar como ser humano. Então, nesse momento, vou aprender a viver com esse povo."

$\mathrm{Na}$ sua chegada, Pari preferiu começar uma formação de francês fora do CAUDA. Ela frequentou durante um mês uma associação que ensina o francês aos estrangeiros e, em seguida, estudou um mês com uma iraniana que lhe deu aulas particulares. Depois disso, veio me ver alegando que não compreendia nada da língua francesa. Eu lhe sugeri recomeçar calmamente do zero. Há cinco meses que nós trabalhamos o francês, e este é um caso bem particular. É uma mulher muito sensível e o menor problema a perturba muito. Há dias em que ela compreende tudo e chega a se expressar bem. No dia seguinte, não se lembra de mais nada, e nós passamos toda a aula sem progredir. Sempre tenta passar pelo inglês para chegar ao vocabulário e às estruturas da língua francesa. Raramente trabalha os exercícios pedidos. Mesmo conhecendo o alfabeto, tem dificuldades de escrever em francês, e, além disso, não há nem pontuação e nem maiúsculas nos seus enunciados. Apesar de tudo isso, Pari progride. Deixa claro o amor que tem por seu país e que sofre de estar em Besançon. Mas, ao mesmo tempo, admira a França e aprecia a acolhida 
que ali recebeu. Há dois meses, foi transferida a um CADA, mas pediu permissão para continuar seu curso de francês no CAUDA. Nesta primeira etapa, Pari viveu bem a clássica contradição dos migrantes: a origem perdida e o enraizamento impossível. Viveu num entre- espaço, entre as bordas do tempo passado que ela não conseguiu esquecer e a do tempo presente a que não conseguiu se agarrar. E mesmo se teve vontade, ainda não tinha sido seduzida pela aprendizagem da língua francesa.

3) Nome: Bekhan

País de origem: Tchetchenia

Idade: 25 anos

Profissão: Economista

Nível de escolarização: Diploma universitário de Economia

Chegada à França: Outubro de 2002.

Percurso migratório: Em 1995, no fim da primeira guerra na Tchetchenia, Bekhan começou seus estudos de Economia. Durante seus anos de estudo, foi pego e agredido pelos "vakhabitas", grupo de fanáticos islamistas que não gostavam que fizesse os estudos num instituto laico. Quando da segunda intervenção russa, no fim de 1999, combatentes tchetchenos que se escondiam nas montanhas lhe confiaram a missão de lhes fornecer medicamentos regularmente. Colocando sua vida em perigo, ele os transportava passando pelos postos de controle das tropas federais. No início de outubro 2002, o que temia aconteceu. Durante a noite, soldados russos vieram revistar sua casa. Encontraram pacotes de curativos e medicamentos em grande quantidade. Após terem agredido toda a família, eles o levaram à prisão local. Durante cinco dias, foi fortemente torturado. Uma noite, um oficial a quem seu pai tinha pago uma grande soma de dinheiro ajudou-o a fugir. Não podendo mais ficar na Tchetchenia, partiu para a Ucrânia e em seguida para a França.

"Neste momento, eu estou sendo acompanhado no hospital de Besançon por causa de traumatismos físicos e morais que sofri. Levando em consideração os fatos expostos, eu peço à OFPRA me acordar o asilo político na França, porque se eu retorno para meu país, isso significa um retorno voluntário para o lugar onde uma execução me espera." 
A entrevista com Bekhan aconteceu em 22 de maio de 2003, na sala de aula. Ele não quis a presença do intérprete.

"Eu falo em russo... com meus amigos tchetchenos, eu falo em tchetcheno. Com os franceses, eu falo em francês [risos], mais ou menos."

"E meu amigo na Tchetchenia me disse para encontrar a Cruz Vermelha e perguntar onde mora o Senhor Tchetcheno em Vesoul."

"Eu morei na casa do meu amigo durante dez dias, depois, segunda vez, Mademoiselle disse "de acordo". Eles encontraram uma vaga para mim no Centro."

"Eu penso que é a primeira coisa [aprender a língua]. $\mathrm{Na}$ escola na Tchetchênia, eu estudava muito, sempre, economia e inglês. Eu falo ainda inglês e o alfabeto inglês e francês é igual. Eu não sei, mas eu falo russo, tchetcheno e inglês. Eu quero ainda falar outras línguas. É possível?"

"E eu estudo muito ainda no meu quarto. Alguns dicionários, alguns livros... eu falo muito com os franceses na rua."

"Não, aqui nada é difícil para mim. Nada... porque sem guerras, sem problemas. Para mim, um lugar para dormir, para comer."

"Oh la la... língua francesa muito difícil para todas as pessoas, para todas. Porque... (longa pausa)"

"Ahn, eu penso que... para mim, primeira coisa é a escola. Eu, eu preciso da escola, depois no quarto, eu leio, eu traduzo, eu trabalho e... terceira coisa é a rua." "Minha língua? Ah, para mim, a língua tchetchena está sempre comigo... minha segunda língua hoje é o francês, porque agora eu moro aqui e preciso ser alguém aqui, com passado, presente e futuro, é isso."

Bekhan começou a formação em francês no CAUDA com um grupo debutante, mas bem rápido eu tive que mudá-lo para um grupo mais avançado. Um mês mais tarde, ele se entediava porque progredia ainda mais rapidamente que o segundo grupo. A partir deste momento, nós decidimos que ele continuaria com três horas de aulas particulares por semana. Bekhan gostava muito de falar dos problemas 
vividos, de sua vida de antes, assim como da sua situação atual e do que ele planejava fazer. Muito atento, ele discutia e comparava os pontos de gramática trabalhados em outras línguas que ele já conhecia. Diferentemente dos outros alunos, falava mais que eu, a professora. Como trabalhava o francês sem parar, dentro do seu quarto, eu sempre lhe dava uma grande carga de exercícios. Foi o aluno que mais tentou se integrar na França. De todo o conjunto de residentes, foi o único que teve uma vida ativa. Frequentava uma academia cinco vezes por semana, três horas por dia e, o mais importante, se sentindo muito à vontade. Ele tomava até mesmo iniciativas de conversação e, à sua maneira, conseguia mantê-las. Seu objetivo era retornar futuramente para a Tchetchenia numa situação de paz. Mas mesmo que não quisesse ficar definitivamente na França, considerava importante aprender bem a língua. No ano de 2004, ele pensava em se matricular na Universidade Aberta para seguir cursos de inglês e economia. Foi um aluno que pedia sempre mais horas de aula, o que não era possível. E, além dos exercícios, ele trabalhava no seu quarto, lentamente, traduções das obras de Alexandre Dumas, seu escritor preferido.

\section{Considerações Finais}

Através dos estudos de caso, numa perspectiva multicultural, nós constatamos que a diversidade presente nos testemunhos dos alunos é também plural: diversidade de nacionalidades, de línguas de origem, culturais (modos de vida, de expressão, representações, relação com valores), de idades, de níveis de escolaridade e de formação, de projetos de vida, de ações, de motivações ao aprendizado da língua francesa.

Esta diversidade plural constitui o estado atual dos grupos de alunos no CAUDA, e ela não pode ser nem negada nem reduzida. Organizar a formação em francês aos "demandeurs d'asile" centrada sobre uma uniformização da prática conduziria ao fracasso. Trata-se de objetivar soluções múltiplas e leves, adaptáveis, ajustáveis ao terreno.

Por outro lado, os estudos de caso colocam também em evidência as identidades. As duas dimensões, diversidade/identidade coexistem e, por consequência, devem ser consideradas juntamente. Após as entrevistas, nós podemos situar as seguintes identidades: identidade de 
desmembramento da sociedade de origem, da opressão socioeconômica, de tendência ao isolamento nos grupos da nacionalidade de origem e de aspiração ao direito de expressão.

Este conjunto de identidades mostra que é preciso velar com atenção para não reduzir os problemas dos "demandeurs" a uma massa de diferenças que não têm nada em comun. Não se trata também de uniformizar, mas de identidades dentro das diversidades. Consideraremos que as práticas e valores culturais (ao mesmo tempo coerentes entre eles e cheios de contradições) dos "demandeurs d'asile" são uma riqueza e não um enfraquecimento. Um dos papéis da formação em francês é colocá-los em relação um com o outro e instaurar entre eles comunicação e abertura.

\section{Referências}

ROCHEBOIS, C. (2003): Les problèmes posés par l'enseignement du français aux demandeurs d'asile du Centre d'accueil d'urgence de Besançon, Mémoire du DEA, Centre de Linguistique Appliquée, Université de Franche-Comté, Besançon.

SIMMEL, G. (1999) : Digressions sur l'étranger, trad. FR., in Grafmeyer Y., Joseph I., L'école de Chicago, Naissance de l'écologie urbaine, Editions du Champ Urbain.

VERONIQUE, D. (1994): Interlangues. Nouvelle Revue d'Ethnopsychiatrie, ${ }^{\circ}$ 25-26, Paris.

Recebido em: abril de 2013. Aprovado em: maio de 2013. 